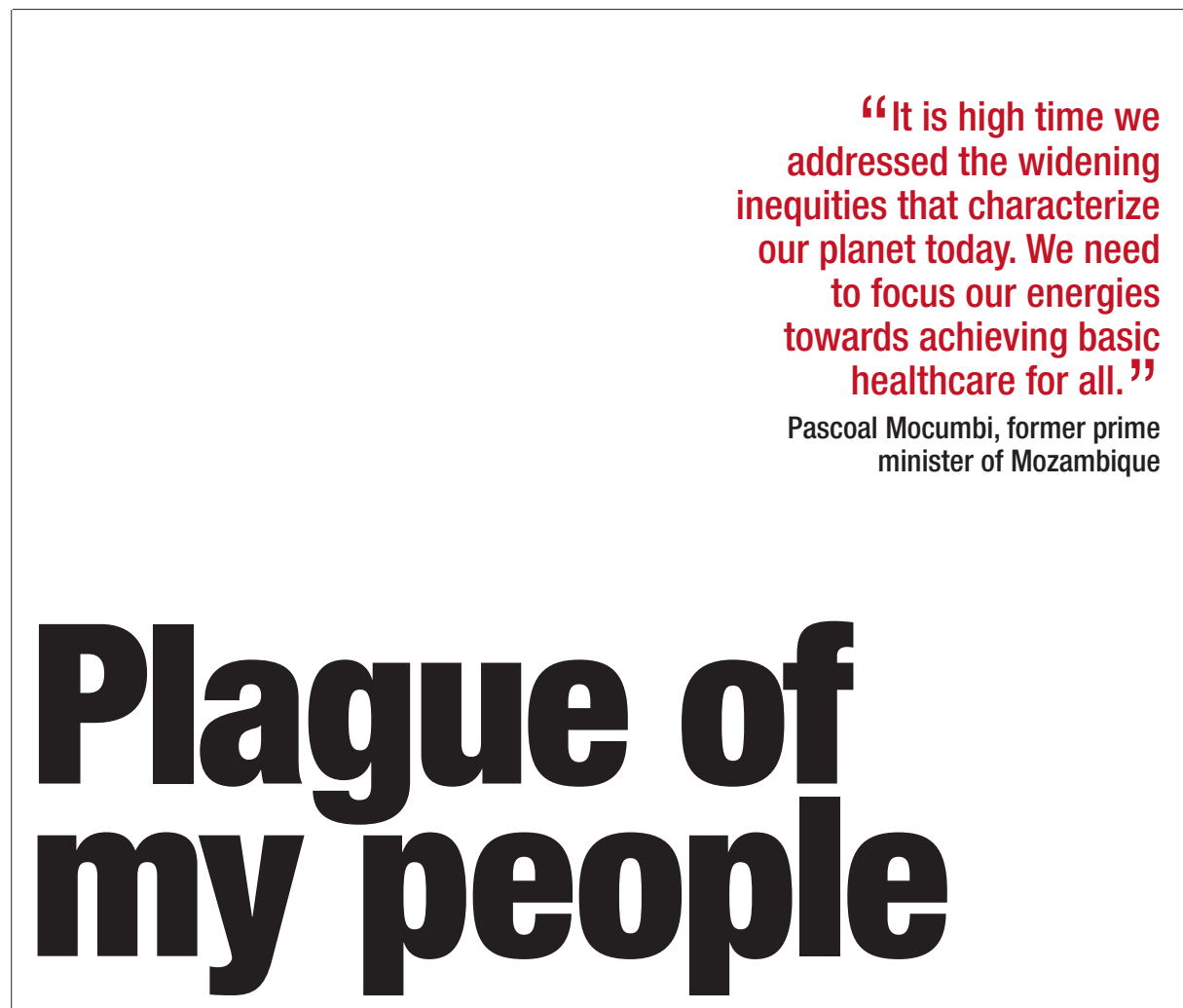

In my country, Mozambique, the entire population is at risk of malaria. One in every four children dies before the age of five and, as in much of Africa, malaria is the biggest cause. The poorest populations are most at risk and the disease often strikes children, women who lose their acquired immunity to malaria during pregnancy, and people who lack any immunity to the disease, such as displaced persons and migrants.

Worldwide, malaria is among humanity's largest — and oldest — health and developmental challenges. It kills more than a million people every year and another 300 million to 500 million people have less severe forms of the disease. Half of the world's population lives in the 103 countries where the whine of a mosquito can herald sickness and death.

Malaria also traps countries in a vicious cycle of poverty and ill health. Sub-Saharan Africa loses an estimated US $\$ 12$ billion every year from its already meagre gross domestic product because of the disease. Progress by African countries in expanding their economies and reducing poverty over the past decade is now endangered by a failure to use our collective knowledge and wisdom to bring medical advances to bear for the benefit of all our citizens.

Many people in Africa consider malaria and its associated suffering to be an inevitable part of everyday life. Parents live in constant fear of this 'fever'. But malaria is an eminently preventable and curable disease if only adequate measures are taken, diagnosis is prompt and effective treatments are available. One day, vaccines

might provide further help to defeat this deadly disease.

Malaria was only recently labelled a tropical disease, after it was successfully controlled in temperate zones in the 1950s and 1960s. Eradication remains a distant dream in Africa. Today sub-Saharan Africa shoulders $90 \%$ of the worldwide malaria burden. The international community cannot with a clear conscience afford to ignore this publichealth crisis any longer - in particular now that there is compelling evidence that public health is intimately linked to development and escaping poverty.

Malaria is returning to regions from which it had disappeared, and drug-resistant parasites are emerging — as are insecticideresistant mosquitoes. These signs should be a wake-up call to politicians and policymakers, and indeed to the public, as to the urgency of working together to develop research and control strategies to contain this scourge.

\section{Radical approach}

Above all, we need to think in radical new ways - ways that show we are more conscious of our common humanity in this third millennium. Ways that make the obligation to help our weakest members the rule and the priority, rather than the exception. And ways in which there is no longer any place for the 'my problem versus your problem' attitude that is still too prevalent in today's otherwise globalized world.

The benefits of scientific innovation must be more equitably shared. Our world is an incredibly complex system, but information and telecommunications technology

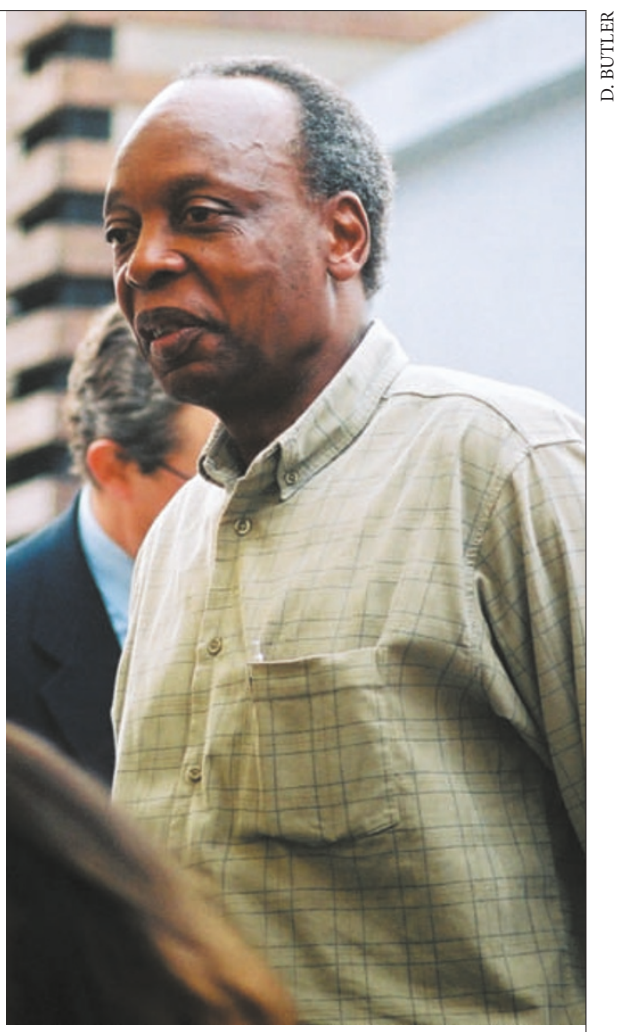

has placed us all in a 'small common hut'. Crucial market-driven, economic transformations must be managed so that they also respect fundamental moral values. It is high time we addressed the widening inequities that characterize our planet today. We need to focus our energies towards achieving basic healthcare for all.

If shared more equitably, humankind's knowledge and resources could enable individuals, communities and nations to take responsibility for their own health and developmental challenges. Recently, new international health initiatives such as the Medicines for Malaria Venture, and the European and Developing Countries Clinical Trials Partnership have begun to accelerate the discovery, development and delivery of new tools to control malaria and other poverty-related diseases.

These are a good start. But such initiatives are often themselves grossly underfunded, while funding and other resources are an order of magnitude short of what is needed for a global push that would make a big impact on the disease.

This Nature supplement should be commended. It highlights the impact of malaria, the efforts of scientists to defeat it, and the political and economic issues that surround it. I hope these articles will inspire greater awareness and more sharply focused, inclusive global health initiatives to address the growing problem of malaria and other neglected diseases.

Pascoal Mocumbi was prime minister of Mozambique from 1994 to February 2004, and is High Representative of the European and Developing Countries Clinical Trials Partnership Programme. 